\title{
Gastric Undifferentiated Carcinoma
}

National Cancer Institute

\section{Source}

National Cancer Institute. Gastric Undifferentiated Carcinoma. NCI Thesaurus. Code C5476.

A carcinoma that arises from the stomach and is characterized by the absence of microscopic features of glandular or squamous differentiation. 